African Journal of Educational Studies in Mathematics and Sciences Vol. 16, No. 2, 2020

\title{
Analysis of misconceptions in chemical equilibrium among senior secondary school students in Ilesa Metropolis in Osun State, Nigeria
}

\author{
N. A. Omilani ${ }^{1}$ and F. D. Elebute ${ }^{2}$
}

\begin{abstract}
Physical chemistry has been an aspect of chemistry which students find difficult at the secondary and tertiary levels of education. In the past, the effort of researchers has been focused on the research that will identify various causal factors which can be attributed to the performance of the learners in this aspect of chemistry. Also, very few experimental studies, has been carried out to improve students' performance. In order to find the right bases for all research that will improve students' achievement, there is a need to profile the misconceptions in the aspect of physical chemistry which is chemical equilibrium. The purpose of this study is to determine students' misconceptions regarding the concepts of chemical equilibrium. To diagnose students' misconceptions in this area, a two-tier multiple-choice question on chemical equilibrium test was administered to 300 high school students in Ilesa Metropolis of Osun- state, Nigeria. Descriptive analysis was used in analyzing the data, students' responses in a Chemical Equilibrium Misconception Test (CEMT) were categorized. The results revealed widespread misconceptions among students in the areas related to (1) equilibrium constant (2) heterogeneous Equilibrium (3) Approach to chemical equilibrium, (4) Application of Le-Chatelier Principle and (5) adding a catalyst.
\end{abstract}

Keywords: analysis, chemical equilibrium, students' misconceptions, chemical equilibrium

\section{Introduction}

There is no doubt in the fact that science and technology is part of our everyday life. Public policy decisions that affect every aspect of our lives are based on scientific evidence. And, of course, the enormous complex natural world that surrounds is full of infinite scientific concepts. As children grow up in an increasingly technologically and scientifically society, they need to be scientifically literate to succeed. Therefore, process of science education, is important and must be given an utmost attention.

Science and chemistry education in particular is a veritable instrument for national development. According to OkonEnoh, (2008) science is a way of seeking information (process) and also an accumulated knowledge resulting from research (products). Okoro (2013) sees science as a systematic investigation of nature with a view to understudy and harnessing them to serve human needs. Chemistry is a compulsory subject among senior secondary school science students in Nigeria due to its relevance. It addresses the needs of majority through its relevance and functionality in content, practice and application. Therefore, chemistry education plays important role in the quality of science teaching and research as well as ensuring

\footnotetext{
${ }^{1,2}$ Nathaniel A. Omilani and F. D. Elebute are in the Department of Science and Technology Education, University of Ibadan, Ibadan, Oyo State Nigeria. Email: <ayonath2002@gmail.com>

Open Access article distributed under the terms of the Creative Commons Attributions License [CC BY-NC-ND 4.0] http://creativecommons.org/licenses/by-nc-nd/4.0. DOI: https://dx.doi.org/10.4314/ajesms.v16i.2.1
} 
that students are equipped with good knowledge to produce intensive goods and services to meet human needs for food, health care products and other materials aimed at improving the quality of life.

Science educators have focused their attention on how students learn and the factors which influenced their learning. Learning is the interaction between what the student is taught and his current idea or concepts. Concepts can be examined in two groups as abstract and concrete ones. While concrete concepts are improved as a result of students' experiences, it is considerably challenging for students to perceive abstract concepts and to improve on it is more difficult.

Chemistry concepts are abstract concepts largely, it is considered to be difficult to comprehend by students (Erdemir, Geban \& Uzuntiryaki 2000). On this particular issue, based on literature, it is clearly stated that students present themselves learning environment, having some sort of thoughts and ideas which are scientifically incorrect by majority. The false information or ideas are called misconceptions (Taber,2017).

The main objective of teaching and learning chemistry concept is to realize a meaningful learning. In order to achieve this, it is required that students should filter the ideas obtained from the external world within their own cognition. Because understanding a chemical concept requires identification at both macroscopic and microscopic level, students may develop several misconceptions as they navigate between the identified levels (Ürek \& Tarhan, 2005; Canpolat, Pınarbaşı, Bayrakçeken \& Geban, 2004; Novick \& Nussbaum, 1981). It is often difficult to explain something which is not visible and has little or no accurate resemblance to reality.
Physical chemistry is an aspect of chemistry that has been widely reported as difficult compared to the organic, inorganic, industrial and analytical aspects most especially at the senior secondary school level in Nigeria (Adesoji, Omilani \& Dada, 2017). One of the explanations that can be provided for this is the fact that students usually have to navigate among the macroscopic, microscopic and symbolic level representations. This is true for all aspects of chemistry but in physical chemistry, students dwell more in the microscopic and symbolic which are abstract.

Chemical equilibrium is an aspect of physical chemistry that does seldom have algorithmic rules. Hence, students used to heuristic reasoning will be unable to solve problems. More often than none, students will have to make sense of graphs which records changes of temperature, pressure or volume of chemical reactions in physical chemistry most especially chemical kinetics (Taber,2017). This deepens the level of abstraction which chemistry is already known for.

In attempting to illustrate and explain chemical equilibrium of chemical many textbooks state that when reaction is about to be at equilibrium, the velocities of forward and reverse reaction increase evenly." "When reaction is at equilibrium, concentrations of reactants are equal to the concentrations of products." These and many are examples of 'misconceptions' of chemical ideas in secondary school text books which are often introduced as analogies to explain chemical equilibrium. In the process, students are often led to develop wrong impressions (Onder \&. Geban, 2006).

There are students with chemistry knowledge which is conceptually wrong, yet 
African Journal of Educational Studies in Mathematics and Sciences Vol. 16, No. 2, 2021

doing very well in algorithmic questions. Mulford (1996), in his dissertation, observed that students can attain high grades in chemistry while still having a high level of misconceptions. There are two major reasons for students having misconceptions in chemistry; firstly, the topics are very abstract (Ben-Zvi et al., 1988), and secondly, words from everyday language are used but with different meanings in chemistry (Bergquist and Heikkinen, 1990). Because students' misconceptions in school sciences at all levels constitute a major problem of concern to science educators, scientist researchers, teachers, and students (Johnstone and Kellett, 1980; Nussbaum, 1981).

Teachers therefore can be astonished to learn that despite their best efforts, students do not grasp fundamental ideas covered in class. Even some of the best students give the right answers but are only using correctly memorized words. When questioned more closely, these students reveal their failure to understand fully the underlying concepts. Besides offering students information and helpful examples, we must show them the reasoning processes that lead to algorithms and conceptual generalizations.

Before misconceptions can be corrected, they need to be identified and properly diagnosed. In order to promote successful learning or at least to simplify it, teachers should diagnose which preconceived images and explanations students hold. Treagust (1988) suggests using specific questionnaires to diagnose misconceptions of content and basic ideas: "By using a diagnostic test at the beginning or upon completion of a specific science topic, a science teacher can obtain clearer ideas about the nature of students' knowledge and misconceptions in the topic', then the teachers become more aware of such misconceptions and are able to discuss them in their classrooms.
After the alternative conceptions of the students are identified, the teacher has to decide how to deal with them. This can be done by giving the scientific idea first and then discussing misconceptions, or go over students' misconceptions first, make them uncomfortable with their own ideas and instruct the scientific concept afterwards.

It has also been established that it is hard to eliminate such misconceptions via the traditional teaching methods (Taber, 2017). Since each student constructs his/her own knowledge, understanding and concepts in accordance with his/her ability and experience, what matters here is, if prior knowledge of student involves any misconceptions, to identify and eliminate misconceptions. In order, to convince students, to free themselves from their original ideas, which is misconceived and to accept the correct idea.

For meaningful learning to take place, it is important that young people have enough opportunities to first express and compare their ideas. Only after children feel uncomfortable with their ideas, the new and current world scientific view should be introduced.

In science and chemistry education research, very few studies give attention to the profiling of students' misconception for the purpose of diagnosis and understanding them in Nigeria. Omilani (2015) argued that experimental studies in chemistry education may successfully improve the pretest scores without doing anything to the misconceptions that these scores conceal. Many students with good grades in chemistry at the O-level enroll in the university physical chemistry perform poorly and this is one of the concerns of this study.

The physical chemistry at the university level requires learner to use many information to make decisions on the 
Analysis of misconceptions in chemical equilibrium among senior secondary school students in Ilesa Metropolis in Osun State, Nigeria

direction of a chemical reaction in the area of chemical equilibrium. Hence, the misconception which were not dealt with at the O-level limits them to solve such problems.

Unfortunately, there are very few studies carried out on misconception diagnosis in Nigeria. Outside Nigeria, identification and understanding of students' misconceptions in various chemistry concepts is at the forefront of improving learning of chemistry. For example, Oetken and Petermann (2007) identified students' pre concepts of combustion.

Also, Barke, Doerfler and Knoop (2008) in an investigation, first instructed middle school classes: 14-16 years old on acids, bases and neutralization. Later, Barke etaal (2008) allowed students to compare their own or other misconceptions from literature in the identified chemistry concepts. So students were first introduced to the scientific idea of the new topic, and afterwards confronted with well-known misconceptions. By comparing the scientific idea and the presented misconceptions the students could intensify Students' Misconceptions and How to overcome the recently gained scientific concept.

Last but not least Barke and Sileshi (2009) formulated a "Tetrahedral-ZPD" chemistry education metaphor as another framework to prevent students' misconceptions "If chemical education is to be a discipline, It has to have a shape, structure, clear and shared theories on which testable hypotheses can be raised. This metaphor re-hybridizes the very powerful 3D-tetrahedral chemistry education concept proposed by Mahaffy (2004); macroscopic, molecular, representational, and human element.

With the idea of the "Zone of Proximal Development (ZPD)" of social constructivist Vygotsky, ZPD should
N. A. Omilani and F. D. Elebute describe "the distance between the actual development level as determined by independent problem solving and the level of potential development as determined through problem solving under adult guidance or in collaboration with more capable peers".

The basic elements of this metaphor are what Shulman (1987) has labeled "Pedagogical Content Knowledge (PCK)" integrated with contextual and research knowledge: "Pedagogy-Content-Context-Research Knowledge (PCCRK). Content knowledge refers to one's understanding of the subject matter, at macro-micro-representational levels; and pedagogical knowledge refers to one's understanding of teaching-learning processes; contextual knowledge refers to establishing the subject matter within significant social-technological-political issues; and research knowledge refers to knowledge of 'what is learned by student?', that is, findings and recommendations of the alternative conceptions research of particular topics in chemistry".

Sileshi and Barke (2007) further conduct an empirical research to evaluate the effects of the Tetrahedral-ZPD Metaphor on students' conceptual change, knowing that high school students in Ethiopia mostly memorize chemical equations without sufficient understanding, that they are not used to thinking in models, or developing mental models according to the structure of matter.

Hence effective teaching should be planned in a way to eliminate those misconceptions. Teachers should awaken to the inadequacy of teaching methods solely consisted of information transfer and use different teaching techniques.

This study therefore, diagnosed the misconceptions in chemical equilibrium so as to reveal the sociocultural uniqueness of 
African Journal of Educational Studies in Mathematics and Sciences Vol. 16, No. 2, 2021

the Nigerian students which could be a basis for deploying a suitable teaching and learning approaches that will solve the problem.

\section{Research questions}

1. What proportion of students have misconceptions in chemical equilibrium?

2. What proportion of students have knowledge of basic concepts in chemical equilibrium but are unable to provide the right reasons?

3. What are students' misconceptions in chemical equilibrium?

\section{Methodology}

The study adopted a descriptive survey design. The population of the study covers all the senior secondary school two students offering chemistry in the urban parts of Ilesa West and East local governments. The sample of the study is three hundred (300) students selected from three secondary schools each from Ilesa West (150) and Ilesa (150) in Osun state Nigeria. The sampling technique used was total enumeration. There only three schools in the urban parts of the two local governments. In each of the schools fifty students were randomly sampled.

In order to diagnose students' misconceptions and their level of understanding of chemical equilibrium, Chemical Equilibrium Misconception Test (CEMT) was developed by the researchers. CEMT contains six items; each item is a two-tier multiple choice chemical equilibrium diagnostic test. The first tier consisted of 6 (six) content question in multiple-choice format with three choices. Each item of the test included one correct choice and two distracters. The second tier consisted of four possible reasons for a possible answer to the first part: three erroneous reasons and one scientifically acceptable reason were supplied. Figure 1 is a sample of the items in CEMT.

Item 1

1. The following hypothetical reaction reaches equilibrium at $25^{\circ} \mathrm{C}$ :

$$
\mathbf{A}_{(\mathrm{g})}+\mathbf{B}_{(\mathrm{g})} \mathbf{C}_{(\mathrm{g})}+\mathbf{D}_{(\mathrm{g})} \text {. }
$$

Once equilibrium has been reached, the concentration of $\mathrm{C}$ is increased by removing $\mathrm{C}$. Assume that the temperature remains constant. Which of the following can be said about the numerical value of the equilibrium constant?
(a) Decreases
(b) Increases
(c) Remains unchanged

\section{Reason}

(1) The rate of reverse reaction increases and the rate of the forward reaction decreases

(2) The rate of reverse reaction increases and the rate of forward reaction stays the same

(3) The ratio between products' concentrations and reactants' concentrations is constant at constant temperature

Source: Elebute (2018)

\section{Figure 1 Sample item in CEMT}


Analysis of misconceptions in chemical equilibrium among senior secondary school students in Ilesa Metropolis in Osun State, Nigeria

N. A. Omilani and F. D. Elebute

During the development stage of the test, first, the instructional objectives of the unit chemical equilibrium were stated. This step was carried out to define the content of the test. Then, students' conceptual difficulties, and misconceptions were identified from previous studies in literature. Items of the test were constructed with respect to misconceptions obtained from literature. It also contains questions on background information on name of school, gender, name of teacher and teachers' qualification.

\section{Validation of instrument}

The face and content validity of CEMT was established by one chemistry teacher and one expert in science education. The test reliability was established using test re test method; it was administered to a class of fifteen students which are not part of the sample study; responses were collected and scored. It was then administered after one week to the same set of students; and scored. The first set of scores was correlated with the second set of scores using Pearson product moment correlation to get a coefficient of 0.71 .

\section{Procedure}

The researcher obtained permission to conduct study from the principals/vice principals of the schools. Chemical equilibrium misconception diagnostics test was administered to students at random in a number appropriate to the number of SSS 2 science students in each school. Two research assistants who were secondary school teachers helped with the retrieval of the instrument.

\section{Scoring of the Instrument and Data} Analysis

The students' responses to the two tiers multiple choice questions were scored 2 marks. One mark was for the content related questions and one mark for the reason. One mark was awarded if the first tier which content related question is correct. No mark is awarded if the first tier which is content related question response is wrong even if the students choose the right option in the second tier. Quantitative data collected were analyzed using descriptive statistics which include frequency count and percentage, thematic analysis was employed to provide answer to the research question.

\section{Results}

Research Question 1

What proportion of students have misconceptions in chemical equilibrium?

Table 1 Number students making right or wrong responses to the two tiers multiple choice items on chemical equilibrium

\begin{tabular}{lcccc}
\hline & \multicolumn{2}{c}{$1^{\text {st }}$ Tier } & \multicolumn{2}{c}{ 2nd Tier } \\
Responses & Right & Wrong & Right & Wrong \\
\hline Item 1 & $250(83.3)^{1}$ & $50(16.7)$ & $100(33.3)$ & $200(66.7)$ \\
Item 2 & $242(80.7)$ & $50(16.7)$ & $62(20.7)$ & $238(79.3)$ \\
Item 3 & $280(93.3)$ & $58(19.3)$ & $80(26.7)$ & $220(73.3)$ \\
Item 4 & $282(94)$ & $18(6)$ & $92(30.7)$ & $208(69.3)$ \\
Item 5 & $286(95.3)$ & $14(4.7)$ & $91(30.3)$ & $209(69.7)$ \\
Item 6 & $224(74.7)$ & $76(25.3)$ & $49(16.3)$ & $251(83.7)$ \\
\hline
\end{tabular}

${ }^{1}$ Percentages in parenthesis 
African Journal of Educational Studies in Mathematics and Sciences Vol. 16, No. 2, 2021

Table 1 shows the number students (with percentages in parenthesis) making right or wrong responses to the two tiers multiplechoice items on chemical equilibrium.

Table 1 reveals that at least $80 \%$ of the students in this study were able to provide the right response in the first tier. This implies that the students have the ability to recall facts related questions in chemical equilibrium.

For example, the first tier of items requires the students to predict what will happen to the equilibrium constant of a chemical reaction $[\mathrm{A}(\mathrm{g})+\mathrm{B}(\mathrm{g})<=>\mathrm{C}(\mathrm{g})+\mathrm{D}(\mathrm{g})]$ in equilibrium at constant temperature, if $\mathrm{C}$ is removed. Table 1 reveals that $83.3 \%$ (250) of the respondents stated that the concentration remains unchanged. Unfortunately, only 100 out of the 300 provided the correct reason for the answer which they choose in the first tier. The correct reason is that the ratio of concentration of product and reactant is constant at constant temperature. And the equilibrium constant is not affected by the change in temperature.

150 respondents could not provide the right reason. They choose options in the second tier related to the factors that affect equilibrium shift. In the equation, if $\mathrm{C}$ were removed, equilibrium will shift to the right and more $\mathrm{C}$ will be formed. This learner used the same rules of equilibrium shift to make decision as regards equilibrium constant.

It is important to also mention that those (50) who cannot provide the correct response for the first tier, also have misconceptions. The fact that they choose the option that indicates that the removal of $\mathrm{C}$ will make the equilibrium constant to increase or decrease, points to the fact that they used macroscopic properties of matter (concentration) to predict the submicroscopic properties of matter (equilibrium constant).
It is imperative to emphasize that if it were a multiple-choice related question (usually with one tier), $83.35 \%$ of the respondent got it right, which will not be considered a poor performance. However, the same learners who got the first tier right, may find it difficult to explain a similar problem in a theory-based items where they have to elaborate the ideas they have.

\section{Research Question two:}

\section{What proportion of students have} knowledge of basic concepts in chemical equilibrium but are unable to provide the right reasons?

Table 1 reveals that many students who provided the right answer in the first tier could not provide the reason for their answer in the second tier. For example, among the 250 responded correctly to the first tier $60 \%$ (150) could not respond to second tier correctly. Similarly, in item $2(74.48 \% ; 180$ out of 242$)$, item $3(71.43 \% ; 200$ out of 280$)$, item $4(67.37 \% ; 190$ out 282), item $5(68.18 \% ; 195$ out of 286$)$ and item 6 $(78.12 \% ; 175$ out of 224$)$ many students could not justify the answer they have provided in the first tier accurately.

\section{Research Question 3}

What are the students' misconceptions in chemical equilibrium?

Items 1 and 5 are related to Equilibrium constant, $66.67 \%$ and $69.67 \%$ of the students respectively shows misconceptions from the reasons picked from the second tiers, it was discovered that most of the students didn't consider whether the reaction is exothermic or not. The students were unable to link the relationships which exist between each of temperature and concentration with equilibrium constant.

Most of the students reasoned that when we increase the temperature, the reaction shifts in the forward direction and thus the 
equilibrium constant increases however they did not pay attention to the direction of reaction changes in exothermic reaction.

In item 2, $79.33 \%$ of the students had misconceptions in the item which is related to heterogeneous equilibrium, and it was discovered from the second tier that most students thought Le chatelier's principle can be applied to all systems However, Equilibrium system is not changed, if the solid is present originally when the system is in equilibrium.

Item 3, $73.33 \%$ of the students had misconceptions and in the analysis it was discovered that students held the conceptions that forwards reaction goes to completion before the reverse one start and some of the students held the conceptions that the total decrease in concentration of $\mathrm{SO}_{2}$ and $\mathrm{O}_{2}$ is equal to the increase in concentration of $\mathrm{SO}_{3}$ and it was seen that student used the law of conservation of mass to predict the changes in concentration of reactants and products when the reaction is approaching equilibrium

Item 4, 69.33\% of student held the conception that le Chatelier's principle can be applied at the initial state when the system as not reached equilibrium. However, le Chatelier principle can only be applied when the system is at equilibrium.

In item $6,83.67 \%$ of the student held the idea that catalyst speed up a reaction to give more product, therefore it speeds up the forward reaction only, however this shows that these students have incomplete understanding of the existences of a common reaction pathway and transition state for both forward and reverse reaction

\section{Discussion}

The teaching of chemistry has traditionally been based on the objectivist view of knowledge; a largely teacher-centered
N. A. Omilani and F. D. Elebute approach where the students learn through rote learning and assessed through ability to regurgitate facts. This is particularly true in Nigeria where the educational system is built largely from a British model; assessed mainly through an exclusively examinationbased model. Students are trained to answer examination questions from past years questions with little or no emphasis on a constructivist approach (Coll \& Taylor, 2001). The result of this study, showed that many of the students who excel in this approach teaching and learning of chemistry, most especially chemical equilibrium; have hidden misconceptions which their ability to regurgitate fact conceals.

The above observation further amplifies the assertion of Omilani (2015) that students' misconceptions in chemistry are usually concealed by their scores. In addition, many students are using the wrong decision rule to predict the equilibrium constant, position of equilibrium and yield. For example, many students failed to limit the le Chattelier principle to reaction in close system and in gaseous state. They were using the same decision rules to predict reactions with products or reactant in the in the solid state. This affirms the observation that made Taber (2017) suggest that chemistry teachers to revise complex ideas in different context to avoid unintended consequences describing the nature of chemistry teaching to avoid unintended consequences such as "undergeneralizations" and "over-generalization" of decision rules as reported in the findings of this study. After the teacher presents the rule for a particular decision making for a concept, the students are likely to have a fixed conception for the use of the same rule for similar situation. Hence it is imperative for the teacher to revisit the old rule that is close to the new rule for a new concept which he is teaching. 
African Journal of Educational Studies in Mathematics and Sciences Vol. 16, No. 2, 2021

\section{Recommendation}

Based on the above findings and conclusions, the following recommendations are made:

- During the teaching and learning of chemical equilibrium, the teacher must emphasize to the learners that the use of Le chatelier's principle cannot be used for decision making when it comes to equilibrium constant.

- Teachers should also use simplified examples when illustrating factors affecting chemical equilibrium, use of Le Chatelier principles and chemical equilibrium so as to avoid the learners having a fixed conception that will be difficult modify.

- The ministry of education should carry out an in-depth analysis of chemistry textbooks used for the teaching and learning of chemistry, with the aim of isolating textbooks which the explanation of the authors could be source of misconceptions to the learners. Authors as well as chemistry teachers should also be made to understand the effect of their misinformation on students learning.

- Schools Management, chemistry teachers as well as parents should ensure that student buy and use only recommended chemistry textbooks.

- The two-tier multiple-choice questions should be introduced as a means of evaluating students' knowledge so as to improve evaluation procedures, which

\section{References}

Ben-Zvi, R., Eylon, B.R., \& Silberstein, J. (1986). Is an atom of copper malleable? Journal of Chemical Education, 63, 6466.

Bergquist, W., and Heikkinen, H. (1990). Student ideas regarding chemical discourages memorization of facts and principles, and which places emphasis on higher cognitive processes.

- Research on analysis of other misconceptions in the other aspect of chemistry should be considered.

- In-service teachers should be trained on how to handle misconception even during instruction. On the part of the preservice chemistry teachers, the methods class should also include studies that will make them: become aware of students' misconceptions in different chemistry concepts, diagnostician of students' misconceptions and have ability to correct students' misconceptions.

\section{Conclusion}

The purpose of teaching and learning of chemistry is beyond passing examination but equipping students with problem solving skills. If the misconceptions of the learners are not diagnosed and corrected, the learners may have distinctions without been able to solve problem in an unfamiliar context. Hence the new trajectory of teaching and learning of physical chemistry and other aspects of chemistry in the secondary school should incorporate the efforts that will solve problems related to students' misconceptions. Therefore, added to the role of chemistry teachers is the role of misconceptions diagnostician and doctor who use the right strategy of teaching to solve the diagnosed misconception.

equilibrium. Journal of Chemical Education 67: 1000-1003.

Bilgin, İ., \& Geban, Ö. (2001). Eliminating misconceptions of High school second grade students on chemical equilibrium by the means of Analogy. Hacettepe University, Faculty of Education Journal,32 
Analysis of misconceptions in chemical equilibrium among senior secondary school students in Ilesa Metropolis in Osun State, Nigeria

Canpolat, N., Pınarbaşı, T., Bayrakçeken, S.,\& Geban, Ö. (2004). Some Comman Misconceptions in Chemistry Gazi University, Faculty of Education Journal,24(1), 135-146.

Coll, R. K.,\&Taylor, N. (2001). Alternative conceptions of chemical bonding held by upper secondary and tertiary students. Res. Sci. Technol. Education, 19 ,

171-191. https://doi.org/10.1080/0263514012005 $\underline{7713}$

Elebute, F. D.(2018) Teachers' Pedagogical Content Knowledge, Effectiveness, Years of Teaching Experience and Students' Misconceptions as a Predictor of Students achievement in Chemical Equilibrium. An Unpublished Maters Dissertation. University of Ibadan, Ibadan, Oyo State, Nigeria.

Erdemir, A., Geban, O., and Uzuntiryaki, E. (2000) Freshman Students' Misconceptions in Chemical Equilibrium. Journal of Chemical Education. 18: 79-84.

Johnstone, A. H., and Kellett, N. C. (1980). Learning difficulties in school sciencetoward a working hypothesis. International Journal of Science Education 2: 171-181.

Mahaffy, P. 2004. The future shape of chemistry Education. Chemistry Education: Research and Practice 5: 229

Metaphor. Muenster (Paper presented at the 3rd Symposium of Chemistry Education, University of Muenster)

Mulford, D. 1996. An inventory for measuring college students' level of misconceptions in firstsemester chemistry, Purdue University.

Novick, S., \& Nussbaum, J. (1981). Pupils' understanding of the particulate nature of matter: A cross-age study. Science Education,65(2), 187-196. https://doi.org/10.1002/sce.3730650209
N. A. Omilani and F. D. Elebute

Nussbaum, J. (1981). Towards a diagnosis by science teachers of pupils' misconceptions: An exercise with student teachers. International Journal of Science Education 3: 159-169.

Okon - Enoh, E.E (2008). Realizing the Goals of National Economic Empowerment and development strategy (NEEDS) and millennium Development goals (MDGS) Implication for science Education Journal of Science Education NOCEN 8 (1) 1 -12.

Okoro S.U.C. (2013) Attaining the MDGs through Effective STAN Education Delivery. STAN 54th Annual Conference proceedings. 108-118.

Omilani, N.A. (2015) Analysis of Chemistry Students' Misconceptions in Volumetric and Analysis in Secondary Schools in Ibadan Metropolis. Unpublished $\mathrm{PhD}$ thesis, Department of Teacher Education, University of Ibadan, Ibadan, Oyo State Nigeria .

Önder, İ., \& Geban, Ö. (2006). The impact of conceptual change texts-based teaching on students' understanding the solubility equilibrium subject. Hacettepe University, Faculty of Education Journal,30, 166-173.

Shulman, L.S. (1987) Knowledge and teaching: Foundation of new reform. Havard Educational Review, 57, 1-22

Sileshi, Barke, H.-D. (2007) Chemistry Misconceptions: Evaluating Remedies Based on Tetrahedral-ZPD

Taber, K.S. (2017) Models and Modelling in Science and Science Education 263278. In Taber, K.S \& Akpan, B.(Ed) Science Education. An International Course Companion. Roterdam, Sense Publisher

Treagust, D.F. (1988) Development and use of diagnostic tests to evaluate students' misconceptions in science. Journal of Science Education 10: 159 
African Journal of Educational Studies in Mathematics and Sciences Vol. 16, No. 2, 2021

Ürek, R., \& Tarhan, L. (2005). A Practice of active Learning based on constructivism to eliminate misconceptions on covalent bonds. Hacettepe University, Faculty of Education Journal, 28,168-177. 

African Journal of Educational Studies in Mathematics and Sciences Vol. 16, No. 2, 2020

Open Access article distributed under the terms of the Creative Commons Attributions License [CC BY-NC-ND 4.0] http://creativecommons.org/licenses/by-nc-nd/4.0. DOI: https://dx.doi.org/10.4314/ajesms.v16i.2.1 